\section{Facebook Use in Malaysian Higher Education Classroom}

Cheng Ean (Catherine) Lee

Department of Communication, School of Arts, Sunway University, Selangor, Malaysia

Department of Educational Research, Faculty of Arts and Social Sciences, Lancaster University, Lancaster, United Kingdom

\section{Synonyms}

Social media; Social networking site; University classroom education; Technology-enhanced learning

\section{Introduction}

Recent studies have shown that social media technology plays a role in facilitating teaching and learning in higher education (Bryant et al. 2014). Social media is recognized as a popular social communication channel, and in recent years, there is an increased interest of educators for using social media in higher education as a technology-enhanced learning environment. In addition, the rapid advancement of technology, such as social media, offers new opportunities to university students for more access to information and interaction, increasing their chances of achieving better academic performance and affecting education in terms of pedagogical purposes (Laskin and Avena 2015).

The use of social media by university lecturers and students has been an interesting research area for educationists and social scientists. The Social Media Survey 2013 by Pearson shows the increase use of social media for teaching by educators and faculty professionals because they see the potential in applying and integrating social media technology to their teaching practices (Seaman and Tinti-Kane 2013). This creates a growing phenomenon for the educational use of social media to create, engage, and share existing or newly produced information between lecturers and students and among students (Lee et al. 2015). Some researchers perceive social media tool as an effective educational platform because it allows educators to make the classes more interactive; on the other hand, there are researchers who state that the use of social media has hindered the achievement of student learning outcomes (Lee et al. 2015).

Although social media is considered a doubleedged sword, research on social media use, such as Facebook, in higher education has grown rapidly with an increasing number of educators and researchers who believe that Facebook provides an environment that supports university students' active learning. Facebook is the most popular social networking site which has received considerable attention from a large number of research areas particularly in social sciences (Manca and Ranieri 2016). Facebook was established in 
February 2004 by Mark Zuckerberg for Harvard University students and later opened for public membership in 2006 (Grossman 2010). To date, Facebook has 2 billion monthly active users (Techcrunch.com 2017). Among them, university and college students hold the highest percentage of active Facebook users, extensively sharing information on Facebook (Abdulahi et al. 2014), and used it as a tool of relaxation and entertainment in between their studies during the university and college days (Kashif 2013).

For example, Facebook groups are used by students for creating discussion forum and receiving updates from their instructors on their newsfeed and by instructors for sharing and communicating with their students about course information, examinations, assignments, and announcements through the group posts (AlBahrani and Patel 2015). Despite the excitements surrounding the potential of Facebook in higher education, researchers have waved the yellow caution flag on the over-privileging the site for actual pedagogical purposes. Some researchers who are not positive about Facebook use reported that the negative feelings were a recognition that the use of Facebook for English language learning simply had not helped improve students' English language (Tess 2013).

Regardless of the pervasive use of Facebook in higher education, there is a mixed result on its perceived impact for teaching and learning in classroom education. With that in mind, this study, part of a work-in-progress research project, provides insight about the adoption of Facebook by lecturers and students in a formal classroom education in Malaysia, as well as how the lecturers and students perceive Facebook could enhance learning experiences, supporting and improving teaching practices. The preliminary findings of this study contribute to the understanding on how and why lecturers and students leverage Facebook as a teaching and learning tool in Malaysian higher education classroom. The remaining sections of this paper is organized as follows: a review of literature on the uses and impacts of Facebook in higher education, a methodology section which describes the procedure of data collection and analysis, a findings and discussion section which present the answers for the two research questions, and lastly a conclusion section which summarizes the findings of this study in achieving the research objectives.

\section{Literature Review}

Research on Facebook use in Malaysian educational contexts has been growing at a rapid rate. The criteria have taken into consideration the inclusion of the studies in this literature review including the scope of study and the academic profile of the journals. Firstly, the selection of literature is based on the uses and impacts of Facebook in higher education. The keywords used for finding these studies are "Facebook and higher education," "Facebook and Malaysian higher education," "Facebook use in higher education," and "uses and impacts of Facebook in higher education." Next, the literature is based on empirical research published in scientific journals, postgraduate theses, dissertations, and other contributions such as conference proceedings and research reports. Lastly the literature is searched through EBSCOhost, Google Scholar, and the Google search engine. The following paragraphs discuss the two themes of the study: uses of Facebook in higher education and impacts of Facebook use in higher education.

Social media, such as Facebook, is an established part of the communication networks and has great potential for networked learning, both within and outside the boundaries of the physical classroom (Freeman 2014). Besides, Facebook has gained a unique position as a learning technology for educational purposes because students created a Facebook group for managing educational content and it provides a conducive environment for student interaction (Ahern et al. 2016). Literature reveals that it is proven to be feasible for learning English in Facebook due to its features which "are able to engage students in meaningful language-based activities" (Kabilan et al. 2010, p. 185). In addition, Manca and Ranieri (2016) in their analysis 
show that Facebook is still mostly considered as an alternative to traditional learning management systems (LMS), though they concluded that the pedagogical affordances of Facebook are still partially implemented.

The use of Facebook by lecturers and students as reported in the literature is due to the "dynamic development of the Web 2.0 and new trends in the social media field" (Tanta et al. 2014, p. 86), and the usage could be explained through the Uses and Gratifications Theory as why and how individuals actively select specific media outlets to satisfy specific needs (Katz et al. 1974, as cited in Ifinedo 2016). Scholarly research has drawn upon the Uses and Gratifications Theory to examine the consumption behavior and motivations of individuals using Facebook information exchange, conformity, freedom of expression, social maintenance and recreation, making new connections, socializing, entertainment, self-status seeking and information, passing time, showing affection, following fashion, sharing problems, demonstrating sociability, and improving social knowledge (Phua et al. 2017).

In the Malaysia context, most researchers agree that the implementation of Facebook in Malaysian higher education produces positive impacts, especially in language and writing classes $(\mathrm{Ng}$ and Maniam 2015) and improving students' academic performance (Helou and Ab. Rahim 2011). Ng and Maniam (2015) investigated the perceptions and attitudes of 15 students from a college in Peninsular Malaysia toward the use of Facebook group discussions. The results show a positive attitude of the college students on the use of Facebook group discussions, and there is a "significant effect of Facebook group discussion on students' writing performances" ( $\mathrm{Ng}$ and Maniam 2015, p. 36). In another research, Helou and Ab. Rahim (2011) measured students' perceptions on the use of social networking sites and its impact on students' academic performance. Based on a survey with 30 undergraduate and postgraduate students of a public university in Southern Peninsular Malaysia, most respondents felt that social networking sites have more positive impact on their academic performance due to its use "for various academic activities such as communicating with the faculty and university authority, communicating with lecturers and supervisors, making academic discussions with classmates and chatting with friends in respect to topics of educational interest. While the negative impacts of the social networking sites towards their academic performance are considerably low" (Helou and Ab. Rahim 2011, p. 7).

Lastly, Facebook also brings benefits in students' learning experience as a platform for online discussion (Abdul Rahman and Mohd Amin 2014), a supplementary tool for team-based learning (Rasiah 2014) and an alternative tool for student engagement (Sim et al. 2014; Haque et al. 2015). Abdul Rahman and Mohd Amin (2014) examined the effectiveness of Facebook as a teaching aid for a subject at a private university in Malaysia. Through a descriptive questionnaire survey with 300 students, the results demonstrate that "the relationship between the students and their lecturers can be improved and this indirectly will influence the students' performance in the subject" (Abdul Rahman and Mohd Amin 2014, p. 333). Rasiah (2014) on the other hand conducted a content analysis on 122 students' reflection journals on their learning experiences of undertaking the group and individual projects as well as their perceptions on the effectiveness of Facebook use in enhancing their learning experience and competences. The author concludes that students perceived the use of Facebook as beneficial for instructional purposes and there is clear evidence on the effective use of Facebook in enhancing team-based learning outside the classroom, complementing face-to-face lessons (Rasiah 2014).

In terms of student engagement, Sim et al. (2014) collected the data through a student survey, postings in the Facebook group, and a short essay from the lecturers concerning their experience of using Facebook as a tool to engage students in the class. Results show that the feedbacks received from both lecturers and students were positive because Facebook features encouraged student participation and engagement in Facebook groups, and the authors conclude that Facebook is the suitable tool for student engagement (Sim et al. 2014). Haque et al. (2015) distributed a structured survey to 500 students of various private and public higher learning institutions in Malaysia. 
Data drawn from 398 usable questionnaires shows that students perceived Facebook as an alternative learning tool in the Malaysian higher learning institutions and "the characteristics of social networking sites such as ease of use, intricacy, adaptability and observability might affect the attitudes towards adoption of Facebook as a learning tool" (Haque et al. 2015, p. 1631).

Prior research shows that Facebook is useful for learning environments (Kabilan et al. 2010) and Malaysian students have been using it for informal learning purposes (Hamat et al. 2012); this in return has resulted a positive impact on their academic performances (Al-Rahmi and Othman 2013). Facebook is perceived as an innovative and effective tool in a student-centered learning environment because it "created a more positive and less-threatening learning environment which enhanced the students' engagement and learning experience while creating a stronger rapport between each other and with the lecturer" (Rasiah 2014, p. 377). In addition, lecturers of Malaysian universities also begin to use Facebook to complement their current teaching and learning practices (Hamid et al. 2011).

Although positive results of Facebook use in higher education were shown in prior literature, differences were found "between the well-proven potential of technology-enabled learning and the less consistent realities of technology use within university teaching and learning" (Henderson et al. 2015, p. 1). Lim et al. (2014) further claimed that successful adoption of Facebook in Malaysian higher education institutions depends on many factors because students, academics, and the institutions themselves have views and practices that do not necessarily align. The use of social media technologies, especially Facebook in higher education, is not an easy and straightforward process. Therefore, more research efforts are needed to integrate social technologies in higher education and for effective use in formal learning contexts (Deng and Tavares 2015).
A mixed result in the empirical literature shows inconclusive evidence on the uses and impacts of Facebook in higher education classroom. Drawing on the literature review of Facebook use in the Malaysia context, two research questions guiding this study are: (RQ1) How is Facebook utilized in Malaysian higher education classroom? (RQ2) How is Facebook perceived as an effective teaching and learning tool in classroom education?

\section{Methodology}

This study took place at two private universities in the Klang Valley, Malaysia. Both universities are known to have a focus on innovative uses of technology in teaching and learning. A qualitative research method, semi-structured interview was adopted. Semi-structured interviews enable researchers to understand how social media technologies such as Facebook is integrated by educators into their teaching because the participants were asked about their expectations and experiences of using the technology as well as the pedagogical choices made when integrating the technology into teaching (Freeman 2014). The most important advantages of using interview are the wealth of detail and focused responses that it provides regardless of the difficulty in generalizing the data and the possibility of not getting the whole truth (Wimmer and Dominick 2014).

A semi-structured interview with three participants - two lecturers and a student - who used Facebook for teaching and learning in classroom education was conducted at their university campus on 11 and 14 January 2017 with an average duration of 46.8 min (ranging from $40.1 \mathrm{~min}$ to $53.1 \mathrm{~min})$. The participants have voluntarily participated in the interviews, and they were able to answer the ten questions asked during the interview. The questions focused on their usage of technologies such as Facebook in higher education classroom, the advantages and disadvantages 
of Facebook use, and the perception on the effectiveness of using Facebook for teaching and learning in classroom education. The participants volunteered to share their experiences and perspectives of using Facebook as a teaching and learning tool in a Malaysian university classroom. The interviews were audio-recorded and further transcribed into 76 single-spaced pages of transcriptions in English. The data from the interviews were content-analyzed using thematic analysis.

\section{Findings and Discussion}

In terms of Facebook usage in the Malaysian higher education classroom, findings indicate that Facebook is a popular networking site used by the lecturers and students as a teaching and learning and communication platform for formal classroom education. The lecturers of two private universities in Malaysia are using Facebook as a platform for students to ask questions about the subject, making announcements and online discussion. An active Facebook user such as a university student has used Facebook group for discussion among peers about lessons and assignment topics. The finding on how Facebook is used in the Malaysian higher education is consistent with the studies of Kabilan et al. (2010), Rasiah (2014), and Haque et al. (2015). Facebook is utilized as an online environment to facilitate learning and communication in the classroom and as "an avenue for a 'formal' academic discourse, whereby explicit assignments and tasks related to learning... could be integrated" (Kabilan et al. 2010, p. 185). It is also used for communication and announcement purposes due to the fact that Facebook is a medium suitable for making announcements (Haque et al. 2015) and useful for managing large classes (Rasiah 2014).

When the lecturer and student participants are asked why they choose to use Facebook for classroom education, the lecturers highlighted that opening a Facebook account is free of charge; it is easier and faster to use Facebook to communicate to students, especially to large group of students; it allows lecturers to feel connected to their students; there is more and better interaction with students; questions about the subject by students were not posted directly to the lecturer but to the class itself which encourages social learning; no constraint of time on Facebook as a way of consultation between educators and students; and students are always on Facebook with their friends; therefore, immediate response can be garnered. These responses reveal the increased use of social media tools such as Facebook for teaching in classrooms by educators and faculty professionals because they see the potential of integrating social media technology to their teaching practices (Seaman and Tinti-Kane 2013).

The student on the other hand claimed that Facebook is becoming common as university students are often on Facebook and they have easy access to Facebook. Besides, students are more likely to read information and material posted on Facebook compared to the university LMS. The student also asserts that it is easier to share knowledge with others on Facebook, whereby all can learn. It is evidenced that students as active users extensively share information on Facebook (Abdulahi et al. 2014) and use Facebook to create, engage, and share existing or newly produced information between lecturers and students and among students (Lee et al. 2015) as well as use it as a tool of relaxation and entertainment in between their study during the university and college days (Kashif 2013).

The findings further support prior literature that Facebook offers benefits in the aspects of student learning experiences (Abdul Rahman and Mohd Amin 2014) and student engagement (Sim et al. 2014; Haque et al. 2015), complementing the current teaching and learning practices (Hamid et al. 2011) and enhancing academic performances (Helou and Ab. Rahim 2011; Al-Rahmi and Othman 2013). The use of Facebook could be explained through the Uses and Gratifications Theory because individuals actively select specific media outlets to satisfy specific needs (Katz et al. 1974, as cited in Ifinedo 2016). Lecturers and student of this study have selected to use Facebook for educational purposes could be motivated to fulfill their needs for information exchange, conformity, 
socializing, entertainment, passing time, and improving social knowledge (Phua et al. 2017).

In assessing the perspectives of the lecturers and students on the impacts of Facebook for teaching and learning in classroom education as addressed in research question 2, all participants express an optimistic view. For example, one of the lecturers looks at Facebook as a positive teaching and learning tool because Facebook enables instant feedback. He argues on how students interact in Facebook is a sign of how well the cohort as a whole is going to perform in the final examination; if those cohorts are active, result is excellent. Another lecturer has used Facebook for online discussion, and she discloses that students are more vocal when they are on Facebook group, even students, who are very quiet, dare to speak out when compared to having a discussion in a physical classroom. These perspectives of the lecturers support the studies of Helou and Ab. Rahim (2011) and Ng and Maniam (2015), in which social networking sites have more positive impact on students' academic performance (Helou and Ab. Rahim 2011), in which the use of Facebook group discussions had significant effect on their performances $(\mathrm{Ng}$ and Maniam 2015). Therefore, Facebook has gained a unique position as a learning technology for educational purposes because Facebook group is created for managing educational content and it provides a conducive environment for student interaction (Ahern et al. 2016).

Nevertheless, the participants also acknowledge some setbacks of using Facebook for classroom education. The negative parts of it are as follows: the small fractions of contributors during online discussion; Facebook is a public domain causing the possibility of having outsiders or general publics who are not registered student to be in the group; distractions on teaching and learning practices; too reliant on a single technology; risk of plagiarism and privacy; and the overlapping between work and school with personal matters on Facebook. For example, the student agrees that distraction is one disadvantage of using Facebook for classroom education; however, she commented that distraction arises regardless of using Facebook or any other platforms. Another disadvantage of Facebook use in higher education reported in prior research was the privacy issue (Smith 2016). Despite privacy being the top of the list of concerns (Seaman and Tinti-Kane 2013), when the student was asked about privacy as a limitation of using Facebook, she claims that it is not a concern for her because she is able to manage her social media account and she is conscious about what to click, what to put on, and how it will reflect on herself. It is noteworthy that the expression on both positive and negative impacts of Facebook use in Malaysian classroom education validates Smith's (2016) conclusion that social media is a doubleedged sword that potentially helps and hinders university teaching and learning.

Lastly, the participants provide their views on the uses and impacts of using Facebook for teaching and learning in Malaysian university classroom. The first lecturer explains that when students are using Facebook, they can remain anonymous, but not faceless. He added that students feel safer this way to ask and respond to a question on Facebook, which becomes a good way for lecturers to assess student learning. The other lecturer agrees that social learning can be encouraged through Facebook discussion because students do not have to wait for the lecturer to respond but among themselves they are learning together. In addition, she implies that she will continue using Facebook to allow students to learn what is supposed to be posted and not. Nevertheless, both lecturers warn that Facebook is not a replacement for missing classes because it is just a supplementary tool, not the end-all tool. According to Haque et al. (2015), Malaysian students perceived Facebook as an alternative learning tool in the Malaysian higher learning institutions.

Additionally, the lecturers reveal that students are reluctant to use their university LMS for learning and communication purposes due to students' comfortability on Facebook and the Facebook interface is more interesting and exciting than their university emails or LMS. Importantly, both lecturers and students acknowledge the positive impact of Facebook on students' academic performances especially the usefulness of Facebook group for assignments discussion. 
The student discloses that Facebook group discussion is effective and helps in student learning because Facebook brings the learning experience outside from the classroom. A similar pattern is evident in existing studies which indicated that Facebook brings benefits in students' learning experience as a platform for online discussion (Abdul Rahman and Mohd Amin 2014), in particular Facebook groups are used by students for creating discussion for assignments through the group posts (Al-Bahrani and Patel 2015).

Despite the benefits of using Facebook in higher education and the ubiquitous usage by students, one study claimed that teachers are hesitant of promoting the use of Facebook in the classroom (Raman et al. 2014), yet both lecturers of this study disagree. The lecturer participants are positive in using Facebook group because they perceive Facebook to be a safe environment for students to learn and they are able to cast a wider net to reach a bigger audience. Rasiah (2014) in her study concluded that Facebook is perceived as an innovative and effective tool in a student-centered learning environment because it enhanced students' engagement and learning experience (Rasiah 2014).

\section{Conclusion}

In this study on the use of Facebook in Malaysian higher education classroom, the goal was to look at the use of a social media technology Facebook - for teaching and learning, and to explore the perception of lecturer and student in considering Facebook for effective classroom education. The findings suggest that the pervasive use of Facebook especially by university students has led to classroom use, and to feel connected to students and instant interactivity are the precursors to technology adoption by the lecturers. Besides, the findings of this study demonstrate similar outcomes with Freeman's (2014) study that the impetus for faculty members to use Facebook as a tool in their classrooms is distinctly pedagogical and not technological. The findings for both research questions concur with the research of Hamid et al. (2011); Hamat et al.
(2012); and Ahern et al. (2016) that Facebook has a unique and powerful position to transform teaching strategies as well as the potential to enhance and improve student learning (Ezell 2016). Thus, this study provides an empirical evidence that complements prior literature on the uses and impacts of Facebook in Malaysian higher education. The participants further recognize and value the benefits of using Facebook for teaching and learning in higher education classroom; hence, this study supports the earlier claim of the pedagogical rationale for using social media technology in classroom education. This study concludes that using Facebook is an opportunity for effective teaching and learning practices in Malaysian higher education classroom.

\section{Cross-References}

Classroom Use, Blended Learning

Social Media and Networks as Digital Instruction and Learning Platforms

- Social Media in Education

- Social Networking and Education

- Technology Enhanced Learning

\section{References}

Abdul Rahman NA, Mohd Amin N (2014) Impact and capability of Facebook as a teaching aid in social science subject at UNITEN. Int $J$ Asian Soc Sci 4 (2):326-333

Abdulahi A, Samadi B, Gharleghi B (2014) A study on the negative effects of social networking sites such as Facebook among Asia Pacific University Scholars in Malaysia. Int J Bus Soc Sci 5(10):133-145

Ahern L, Feller J, Nagle T (2016) Social media as a support for learning in universities: an empirical study of Facebook groups. J Decis Syst 25(Suppl 1):35-49

Al-Bahrani A, Patel D (2015) Incorporating Twitter, Instagram, and Facebook in economics classrooms. J Econ Educ 46(1):56-67

Al-Rahmi WM, Othman MS (2013) The impact of social media use on academic performance among university students: a pilot study. J Inf Syst Res Innov 1-10. Retrieved from http://seminar.utmspace.edu.my/jisri/

Bryant P, Coombs A, Pazio M (2014) Are we having fun yet? Institutional resistance and the introduction of play 
and experimentation into learning innovation through social media. J Interact Media Educ 2(4):1-8

Deng L, Tavares NJ (2015) Exploring university students' use of technologies beyond the formal learning context: a tale of two online platforms. Australas J Educ Technol 31(3):313-327

Ezell P (2016) To like or not to like: Facebook in the higher education classroom. J Teach Learn Technol 5 (1):33-45

Freeman W (2014) Taming social media in higher education classrooms. In: Proceedings for the 9th international conference on networked learning, pp 359-363

Grossman L (2010) Person of the year 2010 mark Zuckerberg. Retrieved from http://content.time.com/ time/specials/packages/article/0,28804,2036683_2037 183,00.html

Hamat A, Embi MA, Hassan HA (2012) The use of social networking sites among Malaysian university students. Int Educ Stud 5(3):56-66

Hamid S, Waycott J, Chang S, Kurnia S (2011) Appropriating online social networking (OSN) activities for higher education: two Malaysian cases. In: Proceedings for Ascilite 2011 Hobart Tasmania Australia, pp 526-538

Haque A, Sarwar A, Ahmad K (2015) Using Facebook as an alternative learning tool in Malaysian higher learning institutions: a structural equation modeling approach. World Acad Sci Eng Technol, Int J Soc Behav Educ Econ, Bus Indus Eng 9(5):1625-1632

Helou AM, Ab. Rahim NZ (2011) The influence of social networking sites on students' academic performance in Malaysia. In: Proceedings for the International Conference on Internet Studies, Kuala Lumpur, Malaysia 2011, pp 1-18

Henderson M, Selwyn N, Aston R (2015) What works and why? Student perceptions of 'useful' digital technology in university teaching and learning. Stud High Educ 1-13

Ifinedo P (2016) Applying uses and gratifications theory and social influence processes to understand students' pervasive adoption of social networking sites: perspectives from the Americas. Int J Inf Manag 36 (2):192-206

Kabilan MK, Ahmad N, Zainol Abidin MJ (2010) Facebook: an online environment for learning of English in institutions of higher education? Internet High Educ 13(4):179-187

Kashif M (2013) Impact of Facebook on students' academic performance: analysis through social capital. Thesis for International Master's Degree Program in Cultural Diversity, University of Eastern Finland. Retrieved from http://epublications.uef.fi/pub/urn nbn_fi_uef-20140038/urn_nbn_fi_uef-20140038.pdf
Laskin AV, Avena J (2015) Introduction of mobile media into formal classroom learning environments. J Mass Commun Educ 70(3):276-285

Lee CE, Sangaran Kutty VS, Wong SP (2015) Exploring the use of Facebook in the classroom: a Malaysia case study. In: Proceedings for the 2nd European conference on social media ECSM 2015, Porto, pp 262-269

Lim JSY, Agostinho S, Harper B, Chicharo J (2014) The engagement of social media technologies by undergraduate informatics students for academic purpose in Malaysia. J Inf Commun Ethics Soc 12 (3):177-194

Manca S, Ranieri M (2016) Is Facebook still a suitable technology-enhanced learning environment? An updated critical review of the literature from 2012 to 2015. J Comput Assist Learn 32:503-528

$\mathrm{Ng}$ SP, Maniam M (2015) The effectiveness of Facebook group discussions on writing performance: a study in matriculation college. Int J Eval Res Educ 4(1):30-37

Phua J, Jin SV, Kim J (2017) Uses and gratifications of social networking sites for bridging and bonding social capital: a comparison of Facebook, Twitter, Instagram, and snapchat. Comput Hum Behav 72:115-122

Raman A, Mohd Sani R, Kaur P (2014) Facebook as a collaborative and communication tool: a study of secondary school students in Malaysia. In: Proceedings for the international conference on communication and media 2014 (i-COME'14) 155(October), pp 141-146

Rasiah RRV (2014) Transformative higher education teaching and learning: using social media in a teambased learning environment. Procedia Soc Behav Sci 123:369-379

Seaman J, Tinti-Kane H (2013) Report for Pearson learning solutions: social media for teaching and learning. Boston

Sim TY, Naidu D, Apparasamy D (2014) Improving students engagement through social media: a case study of a private university in Malaysia using Facebook. Int J eEduc, e-Bus, e-Manag e-Learn 4(6):396-409

Smith EE (2016) "A real double-edged sword:" undergraduate perceptions of social media in their learning. Comput Educ 103:44-58

Tanta I, Mihovilović M, Sablić Z (2014) Uses and gratification theory - why adolescents use Facebook? Medijska istraživanja 20(2):85-110

Techcrunch.com (2017) Facebook now has 2 billion monthly users... and responsibility. Retrieved from https://techcrunch.com/2017/06/27/facebook-2-billion -users/

Tess PA (2013) The role of social media in higher education classes (real and virtual) - a literature review. Comput Hum Behav 29(5):A60-A68

Wimmer RD, Dominick JR (2014) Mass media research: an introduction, 10th edn. Wadsworth Cengage Learning, Boston 